\title{
TOLERÂNCIA DE CULTIVARES DE MILHO AO TEMBOTRIONE
}

DUARTE, Rafaelle Ribeiro ${ }^{1}$; FREITAS, Rogério Soares de ${ }^{2}$; NASCIMENTO, Cleiton Alexandre Silveira do ${ }^{3}$; SILVA, Pedro Henrique Giova da ${ }^{4}$; BORGES, Wander Luis Barbosa ${ }^{2}$; ZOZ, André ${ }^{5}$

ISSUE DOI: $10.3738 / 1982.2278 .3623$

\begin{abstract}
RESUMO: O presente trabalho teve objetivo avaliar a tolerância dos cultivares de milho IAC 8390, IAC 8333 e IAC Airan ao herbicida tembotrione. O experimento foi instalado em uma área experimental no Centro de Seringueira e Sistemas Agrofloretais do Instituto Agronômico - IAC, localizado em Votuporanga-SP, conduzidos no delineamento em blocos casualizados, com cinco repetições, em arranjo fatorial 4 × 3 × 2 , sendo o primeiro fator constituído por cultivares de milho, o segundo por doses dos herbicidas: tembotrione $(0 ; 50,4 ; 100,8$ e 201,6 g i.a. ha ${ }^{1}$ ) e o terceiro fator em estádios fenológicos das plantas (V3 e V6). Após a aplicação dos herbicidas foi avaliada a fitotoxicidade e, no momento da colheita do milho, a altura de plantas, a população final de plantas, a massa de 100 grãos, o índice de espigas e a produtividade de grãos. Nas condições em que o trabalho foi realizado, verificou-se que o herbicida tembotrione apresenta baixa fitotoxicidade aos cultivares de milho IAC 8390, IAC Airan e IAC 8333, independentemente da dose ou época de aplicação em relação ao estádio de desenvolvimento da cultura (V3 ou V6).
\end{abstract}

Palavras-chave: Zea mays. Seletividade. Herbicidas.

\section{MAIZE CULTIVARS TOLERANCE FOR TEMBOTRIONE}

SUMMARY: The present work had the objective of evaluating the tolerance of maize cultivars IAC 8390, IAC 8333 and IAC Airan to the herbicide tembotrione. The experiment was carried out in an experimental area at the Center of Rubber Tree and Agroforestry Systems of the Agronomic Institute - IAC, located in - Votuporanga, São Paulo State, Brazil, conducted in a randomized complete block design with five replications, in a factorial arrangement $4 \times 3 \times 2$, the first factor was maize cultivars, the second by herbicide doses: tembotrione $(0,50.4,100.8$ and $201.6 \mathrm{~g} \mathrm{ia} \mathrm{ha}^{-1}$ ) and the third factor in plant phenological stages (V3 and V6). After herbicide application, phytotoxicity was evaluated, and, at the time of maize harvest, the height of plants, the final population of plants, the mass of 100 grains, ear index and grain productivity. Under the conditions in which the work was carried out, it was verified that the herbicide tembotrione presents low phytotoxicity to maize cultivars IAC 8390, IAC Airan and IAC 8333 , regardless of the dose or time of application in relation to the stage of development of the crop (V3 or V6).

Keywords: Zea mays. Selectivity. Herbicides.

\section{INTRODUÇÃO}

No Brasil, na safra 2017/18, a área semeada com milho foi de 16,64 milhões de hectares, com produção de 81,35 mil toneladas, produtividade de $4891 \mathrm{~kg} \mathrm{ha}^{-1}$, resultando no faturamento de $\mathrm{R} \$ 40,56$ bilhões no setor (CONAB, 2018). Em geral o país ocupa a terceira posição na produção mundial, atrás apenas dos Estados Unidos e da China (FAO, 2017).

O milho é cultivado em 3,6 milhões de propriedades agrícolas no Brasil, e existem várias condições para o cultivo desse cereal, desde agriculturas de subsistência até grandes produtores que utilizam o mais alto nível tecnológico obtendo grandes produtividades (EMBRAPA, 2012).

\footnotetext{
${ }^{1}$ Mestranda em Agronomia - Universidade Estadual do Mato Grosso do Sul - UEMS, Cassilândia, MS, Bolsista da PIBAP (MS)

${ }^{2}$ Pesquisador Científico, Dr. - IAC - CAP Seringueira e Sistemas Agroflorestais, Votuporanga, SP;

${ }^{3}$ Graduando em Agronomia - Universidade Estadual Paulista - UNESP, Dracena, SP;

${ }^{4}$ Graduando em Agronomia - Universidade Estadual Paulista - UNESP, Ilha Solteira, SP;

${ }^{5}$ Pesquisador Visitante - IAC - CAP Seringueira e Sistemas Agroflorestais, Votuporanga, SP.
} 
Para atender ao alto nível tecnológico empregado pelo agricultor brasileiro há predominância de cultivares de híbridos simples disponíveis no mercado. Segundo Cruz et al. (2014), 56,15\% dos cultivares disponíveis no mercado são híbridos simples, seguido por 18,6\% de híbridos triplos, 13,56\% de híbridos duplos e as variedades completam as opções de mercado com $11,68 \%$.

Não menos importante que os demais tipos de cultivares, as variedades atendem um nicho de mercado que requer sementes de baixo custo em relação aos híbridos, associado ao fato de que é possível reutilizar as sementes por alguns anos, sem redução significativa na produtividade de grãos. Este tipo de cultivar é de grande importância em regiões onde a utilização de sementes híbridas torna-se mais inviável devido às condições econômicas e econômico-sociais, mais precárias e, consequentemente, uso de baixa tecnologia na cultura do milho (EMBRAPA, 2015).

Um dos fatores que afetam a produtividade de milho é a interferência das plantas daninhas, que competem com a cultura por água, nutrientes, espaço, além, de hospedar pragas e doenças. Neste sentido, o controle de plantas daninhas é uma prática de grande importância para a obtenção de altos rendimentos em qualquer exploração agrícola. A interferência das plantas daninhas tende a aumentar o custo de produção, reduzir as margens de lucro e diminuir a qualidade do produto (CONSTANTIN; OLIVEIRA, 2005). Embora considerada uma planta de rápido crescimento, a cultura do milho sofre intensa inteferência dessas plantas, com queda expressiva de produtividade de grãos (KOZLOWSKI, 2002; BLANCO et al., 1976). Desse modo, o uso de herbicidas é necessário para exploração econômica de grandes áreas de cultivo e, muitas vezes também, em pequenas áreas, devido à escassez e o custo da mãode-obra no meio rural.

Embora os herbicidas sejam uma ferramenta importante para uso no manejo de plantas daninhas para cultura do milho, seu uso requer o conhecimento prévio da seletividade do herbicida aos cultivares de milho que se pretende utilizar. Neste sentido, a seletividade dos herbicidas ocorre devido aos seguintes fatores: posicionamento do herbicida no tempo e no espaço; dosagem e formulação; metabolismo diferencial entre cultura e planta daninha; diferenças anatômicas entre cultura e plantas daninhas; resistência no local de ação; uso de protetores de culturas; fatores internos da planta que não metabólicos; diferenças entre as plantas daninhas e culturas nos diferentes estádios fenológicos, aplicação de substâncias adsorventes, cultivar, tamanho da semente e engenharia genética (VIDAL, 1997; OLIVEIRA JÚNIOR, 2001).

Trabalhos de pesquisas realizados com herbicida nicosulfuron, importante herbicida para manejo de plantas daninhas na cultura do milho, expõe a particularidade da seletividade desse herbicida à cultura. Assim, existe uma grande diferença de tolerância de híbridos de milho aos herbicidas pós-emergentes, podendo ser elevada para alguns e reduzida para outros. Em muitos casos, híbridos considerados tolerantes a esses herbicidas podem apresentar sensibilidade, dependendo do estádio de desenvolvimento da planta, do ambiente e da dose utilizada (MORTON; HARVEY, 1992; GUBBIGA et al., 1995). Estudo realizado por López-Ovejero et al. (2003) mostra que a tolerância dos cultivares de milho ao herbicida nicossulfuron é dependente do estádio fenológico no momento da aplicação, da dose utilizada, do intervalo entre a aplicação do herbicida e a do inseticida organofosforado, ou da adubação nitrogenada de cobertura. Outros resultados realizados por Cavalieri et al. (2008), McMullan e Blackshaw (1995); Buzatti (2000); Spader e Vidal (2001) reforça a necessidade de se estudar o comportamento de cultivares de milho quanto à tolerância a herbicidas.

A seletividade é a capacidade de um determinado herbicida eliminar plantas daninhas que se encontram no mesmo ambiente da cultura sem causar danos fitotóxicos capazes de reduzir a produtividade e/ou prejudicar a qualidade do produto colhido. A seletividade é, portanto, detectada por meio de avaliações de fitotoxicidade e do rendimento da cultura (VELINI et al., 1992). A análise da fitotoxicidade 
é baseada em alterações na coloração das plantas, resultando em queda na produtividade da cultura comparada com as plantas da testemunha sem aplicação. Quanto maior a tolerância da cultura e do híbrido utilizado em relação ao herbicida, maior é a segurança da aplicação (OLIVEIRA; CONSTANTIN, 2001). Contudo, Damião Filho (1996) ressalta que mesmo na ausência aparente de sintomas de fitotoxicidade na planta de milho, a produtividade final da cultura pode ser reduzida pela aplicação do herbicida. Neste sentido, como reforça Nicolai (2004), o herbicida a ser empregado deve ser preferencialmente seletivo para a cultura, não causar injúrias às plantas de milho, tanto à parte aérea quanto ao sistema radicular, visto que inúmeras condições de uso podem causar distintos efeitos fitotóxicos e redução da produtividade final. Já Fancelli et al. (1998) observaram sensíveis reduções de rendimento de lavouras de milho provocados por grande parte dos herbicidas recomendados para a cultura. Estes fatos reforçam a necessidade de avaliação, em condições de campo, da influência dos principais herbicidas aplicados em pré e pós-emergência sobre o desempenho da cultura de milho.

O herbicida tembotrione (2-\{2-Chloro-4-mesyl-3- [(trifluoroethoxy)methyl] benzoyl \}cyclohexane-1,3-dione), pertence ao grupo químico das tricetonas, inibidores da enzima 4hidroxifenilpiruvatodioxigenase (HPPD) que atua na síntese de carotenoides desenvolvendo uma intensa coloração esbranquiçada nas folhas das plantas sensíveis, evoluindo para uma seca e morte subsequente. Esse resultado ocorre devido à degradação oxidativa da clorofila e das membranas fotossintéticas (GROSSMANN; EHRHARDT, 2007). Sendo assim, o mesmo pode ser uma ferramenta importante no manejo de plantas daninhas, quando rotacionado com herbicidas de mecanismos de ação diferentes, pois apresenta eficiência de controle de várias espécies daninhas dicotiledôneas e de monocotiledôneas na cultura do milho (WILLIAMS; PATAKY, 2008).

Diferentemente do nicosulfuron, no qual a resposta dos híbridos à aplicação do herbicida é bastante variável (CAVALIERI et al., 2008), o tembotrione tem sido seletivo aos cultivares de milho (SPADER et al., 2008; KARAM et al., 2009). Ademais, este herbicida não exige manejo especial em relação à adubação com ureia em cobertura para a cultura do milho (DAN et al., 2009). Entretanto, segundo Schuelter et al., (2018), a aplicação desse herbicida em campos de linhagens e de populações segregantes, obtidas a partir de alguns cruzamentos com genótipos tolerantes, tem revelado o aparecimento de sintomas de fitotoxicidade, indicando a existência de fatores genéticos que conferem sensibilidade ao nicosulfuron e tembotrione.

Neste contexto, o uso de herbicida torna-se mais preocupante quando se utiliza variedades de polinização aberta ou híbridos intervarietais uma vez que é da natureza dessa cultivar maior variabilidade e desuniformidade entre as plantas de uma lavoura, podendo desse modo afetar esses cultivares em maior magnitude e, até mesmo, inviabilizar o uso dessas moléculas no manejo de plantas daninhas na cultura. Diante do exposto, este trabalho foi realizado com objetivo de avaliar a tolerância dos cultivares de milho IAC 8390, IAC 8333 e IAC Airan ao herbicida tembotrione.

\section{MATERIAL E MÉTODO}

O experimento foi instalado em um Latossolo Vermelho eutrófico, B textural, câmbico, textura média, profundo e com boa drenagem, em área experimental do Centro Avançado de Pesquisa de Seringueira e Sistemas Agroflorestais, do IAC, localizado em Votuporanga, São Paulo. A análise química apresentou matéria orgânica $=19 \mathrm{~g} \mathrm{dm}^{-3}, \mathrm{pH} \mathrm{em} \mathrm{CaCl}_{2}=5 ; \mathrm{P}_{\text {resina }}=55 \mathrm{mg} \mathrm{dm}^{-3}$ e 2; 21; 5 e $18 \mathrm{mmol} \mathrm{dm}^{-3}$ respectivamente de $\mathrm{K}, \mathrm{Ca}^{+2}, \mathrm{Mg}^{+2}$ e $\mathrm{H}+\mathrm{Al}$.

A área experimental foi cultivada anteriormente com milheto, sendo dessecado quimicamente aos 20 dias antes da semeadura do milho, com 1080,0 g i.a. ha ${ }^{-1}$ de ghyphosate. As plantas daninhas que 
surgiram durante o ciclo da cultura do milho foram eliminadas por capina manual.

A semeadura foi realizada em sistema de semeadura direta no verão. Imediatamente antes da sua realização da semeadura foram formados sulcos espaçados de $0,80 \mathrm{~m}$ entre si, utilizando uma semeadora, os quais receberam o equivalente a $330 \mathrm{~kg} \mathrm{ha}^{-1}$ do adubo formulado 08-20-20. Nesses sulcos foi realizada a semeadura, utilizando matraca experimental, posicionando duas sementes por ponto, a uma profundidade de 2-3 cm, totalizando 25 plantas por linha de $5 \mathrm{~m}$ de comprimento, para obtenção de uma população de 62500 plantas por hectare. A população foi ajustada com desbaste realizado aos sete dias após a emergência (DAE) da cultura.

O delineamento experimental de blocos ao acaso, com cinco repetições, em esquema fatorial $4 \times 3 \times 2$. Assim, o ensaio foi composto por quatro doses do herbicida tembotrione $(0 ; 50,4 ; 100,8$ e 201,6 g i.a. ha $^{-1}$ ), três cultivares de milho (dois híbridos intervarietal IAC 8390 e IAC 8333 e a variedade IAC Airan) e o herbicida aplicado em dois estádios de desenvolvimento da cultura (V3 - três folhas desenvolvidas e V6 - seis folhas desenvolvidas).

Cada parcela foi constituída por seis linhas de $5 \mathrm{~m}$ de comprimento, sendo a área útil de cada parcela composta por duas linhas centrais. A emergência das plântulas de milho ocorreu cinco dias após a semeadura.

Ademais, a adubação de cobertura, com $80 \mathrm{~kg}$ de $\mathrm{N}_{\text {ha }}{ }^{-1}$ na forma de sulfato de amônio foi realizada aos sete dias após a aplicação dos tratamentos herbicidas. Assim, foi observado o intervalo de sete dias entre a adubação de cobertura nitrogenada e a aplicação dos herbicidas e não foi utilizado o inseticida organofosforado para controle da lagarta-do-cartucho.

Para aplicação dos tratamentos utilizou-se pulverizador costal pressurizado com $\mathrm{CO}_{2}$, com pressão constante de $250 \mathrm{kPa}$, equipado com barras de duas pontas tipo leque TT11002, com volume de $150 \mathrm{~L} \mathrm{ha}^{-1}$ de calda.

As condições meteorológicas no momento da aplicação dos herbicidas foram de céu claro, velocidade do vento inferior a $5 \mathrm{~km} \mathrm{~h}^{-1}$, solo úmido, temperatura do ar de $27{ }^{0} \mathrm{C}$ e umidade relativa do ar de $63 \%$.

Na Figura 1A e 1B estão representados os dados de precipitação, temperatura mínima e máxima, registrados durante o ciclo da cultura. 
Figura 1. Temperatura máxima, média e mínima (A) e pluviosidade decendial (B) durante o período de condução do experimento, Votuporanga, SP. Fonte: CIIAGRO.
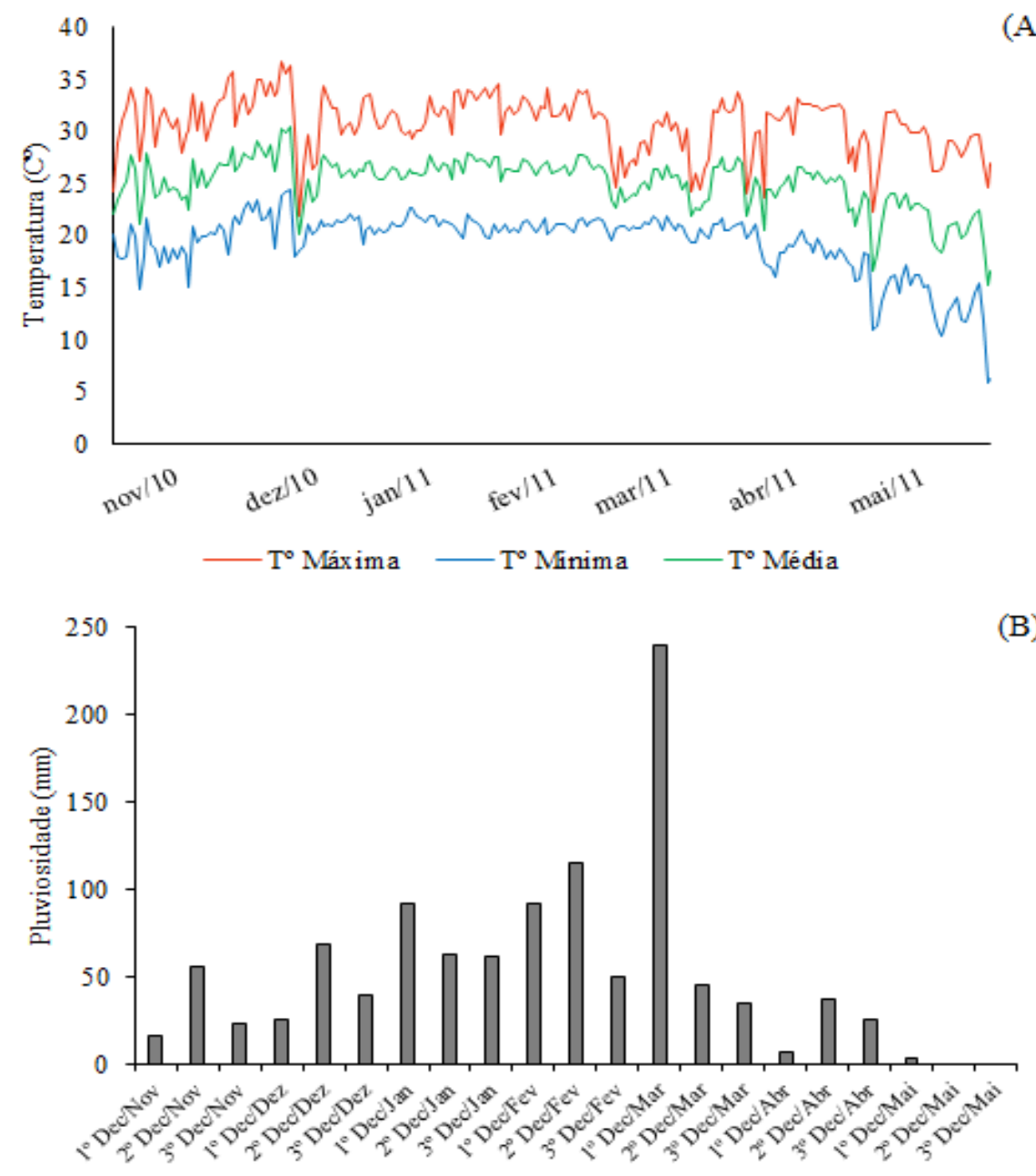

As avaliações de fitotoxicidade foram realizadas por meio de notas de acordo com os sintomas visuais causados pelos herbicidas nas plantas, aos 7, 14, 21 e 28 dias após a aplicação (DAA) dos tratamentos. Valores de 0 a $100 \%$ foram atribuídos em função da intensidade dos sintomas, sendo 0 a ausência de sintomas e 100\% a morte da parte aérea da planta. Esses valores foram sempre tomados em comparação com o tratamento testemunha, sem aplicação de herbicidas (Sociedade Brasileira da Ciência das Plantas Daninhas, 1995). Sendo os resultados apresentados com seus respectivos erros padrão.

$\mathrm{Na}$ colheita foram avaliadas a população de plantas (plantas ha ${ }^{-1}$ ), altura de planta (medida do nível do solo até o final da inflorescência masculina - pendão) e altura de espiga (medida do nível do solo até a inserção da espiga) $(\mathrm{cm})$ obtida em 10 plantas por parcela, massa de 100 grãos $(\mathrm{g})$, rendimento de espigas (porcentagem de grãos $(\mathrm{m} / \mathrm{m})$ em relação às brácteas e sabugo) e a produtividade de grãos (kg ha $\left.{ }^{1}\right)$, com umidade corrigida para $13 \%$.

Como os cultivares possuem diferentes potenciais produtivos, os dados foram transformados em porcentagem em relação à testemunha para possibilitar a comparação entre eles. Neste sentido, apenas na Tabela 1 os dados utilizados dos três cultivares não foram transformados para porcentagem, sendo os mesmos obtidos pelas testemunhas sem aplicação de herbicidas utilizando 10 repetições de cada cultivar para a análise. Essa tabela tem objetivo de demonstrar que os cultivares apresentaram desenvolvimento normal, representado pelos parâmetros agronômicos avaliados e pela produtividade alcançada. 
Os dados foram submetidos à análise de variância e se fez o desdobramento das interações; em seguida, procedeu-se ao teste de Tukey a $5 \%$ de probabilidade e análise de regressão. Os modelos de regressão foram escolhidos em função da significância dos coeficientes de regressão, utilizando-se o teste t a $5 \%$ de probabilidade, do coeficiente de determinação e do significado biológico.

\section{RESULTADO E DISCUSSÃO}

De modo geral o ensaio apresentou desenvolvimento das plantas de acordo com o potencial genético dos cultivares (IAC, 2019), indicando que o ensaio foi conduzido em condições apropriadas para o desenvolvimento das plantas (Tabela 1). Nesta tabela também se verifica que os cultivares IAC 8390 e IAC 8333 foram os mais produtivos com produtividade superior a $8 \mathrm{t} \mathrm{ha}^{{ }^{1}}$.

Tabela 1. Médias de altura de planta (ALTP), altura de inserção da espiga (ALTE), rendimento de espiga (REDE), população de plantas (POP), índice de espigas (INDE), massa de cem grãos (M100), peso do hectolitro (PH) e produtividade de grãos (PRODG), das testemunhas para caracterização de três cultivares de milho. Votuporanga-SP, 2019.

\begin{tabular}{|c|c|c|c|c|c|c|c|}
\hline \multirow{2}{*}{ Cultivar } & ALTP & ALTE & REDE & POP & M100 & PH & PRODG \\
\hline & \multicolumn{2}{|c|}{----------cm---------- } & $\%$ & Plantas ha ${ }^{-1}$ & ----- g--- & & $--\mathrm{kg} \mathrm{ha}^{-1}--$ \\
\hline IAC 8390 & $231,6 \mathrm{a}$ & $116,7 \mathrm{a}$ & $76,27 \mathrm{a}$ & 62500 & 31,94 & 772,5 & $8323 \mathrm{a}$ \\
\hline IAC Airan & $219,1 \mathrm{~b}$ & $113,0 \mathrm{a}$ & $72,46 \mathrm{~b}$ & 58906 & 32,66 & 769,5 & $6384 \mathrm{~b}$ \\
\hline IAC 8333 & $215,1 \mathrm{~b}$ & $104,9 \mathrm{~b}$ & $75,91 \mathrm{a}$ & 62188 & 32,27 & 766,5 & 8040 a \\
\hline C.V. (\%) & 4,39 & 6,44 & 1,31 & 8,09 & 3,2 & 1,40 & 10,68 \\
\hline
\end{tabular}

Médias seguidas da mesma letra na coluna não diferem entre si pelo teste de Tukey a 5\% de probabilidade.

$\mathrm{Na}$ Tabela 2 verifica-se que ocorreu efeito de cultivar para as variáveis, população de plantas (POP) e rendimento de espiga (REDE), efeito de estádio de aplicação do herbicida para as variáveis, altura de planta (ALT) e massa de cem grãos (M100). A interação cultivar (C) x estádio de aplicação do herbicida (E) foi significativa para variável rendimento de espiga.

Tabela 2. Resumo da variância das características agronômico de três cultivares de milho submetido a doses do herbicida tembotrione em dois estágios de desenvolvimento da planta. Votuporanga-SP, 2019.

\begin{tabular}{|c|c|c|c|c|c|c|c|c|}
\hline \multicolumn{9}{|c|}{ Quadrado Médio } \\
\hline F.V. & GL & ALTP & ALTE & REDE & POP & PH & M100 & PRODG \\
\hline Bloco & 4 & 26,19 & 244,16 & 1,49 & $366,86^{*}$ & 3,39 & $67,50^{* *}$ & 341,33 \\
\hline Cultivar (C) & 2 & 56,50 & 402,45 & $11,65^{*}$ & $464,03^{*}$ & 6,46 & 3,33 & 98,27 \\
\hline Época (E) & 1 & $121,04^{*}$ & 8,10 & 0,09 & 234,58 & 0,82 & $217,35^{* *}$ & 76,27 \\
\hline Dose (D) & 3 & 19,43 & 173,37 & 3,15 & 113,80 & 0,25 & 12,75 & 252,53 \\
\hline $\mathrm{CxE}$ & 2 & 62,14 & 43,92 & $11,55^{*}$ & 116,33 & 5,88 & 7,01 & 131,75 \\
\hline$C \times D$ & 6 & 11,38 & 198,15 & 3,02 & 74,97 & 1,27 & 1,62 & 64,24 \\
\hline Ex D & 3 & 19,15 & 122,46 & 1,98 & 192,19 & 1,42 & 35,98 & 129,42 \\
\hline$C \times E \times D$ & 6 & 12,76 & 94,79 & 1,95 & 56,57 & 1,32 & 24,51 & 131,07 \\
\hline Resíduo & 92 & 24,95 & 160,02 & 3,30 & 118,13 & 3,23 & 17,47 & 242,62 \\
\hline C. V. (\%) & & 4,94 & 12,44 & 1,80 & 10,81 & 1,80 & 4,16 & 15,18 \\
\hline
\end{tabular}


Já a fitotoxicidade, de modo geral, foi baixa e menor quando o herbicida foi aplicado nas plantas com três folhas desenvolvidas (Figura 2), demonstrando que mesmo em elevadas doses do herbicida não resultou em maior intensidade de sintomas.

$\mathrm{Na}$ aplicação no estádio V3 do milho, foi possível verificar que os cultivares apresentaram níveis de fitotoxicidade inferiores a $20 \%$, sendo que o cultivar IAC Airan apresentou maiores níveis para a maior dose, aos 14 DDA (18\%) e aos 28 DDA (19\%). O cultivar IAC 8390 apresentou valores baixos para todas as doses do herbicida, com notas de $11 \%$ aos 7 e 14 DDA, e $12 \%$ aos 28 DDA.

Os sintomas característicos do herbicida tembotrione, segundo Karan et al. (2009), é o desenvolvimento de uma intensa coloração esbranquiçada evoluindo para seca e morte subsequente das plantas em cultivares sensíveis. No presente trabalho não foram observados sintomas mais severos nas plantas, exceto em $1 \%$ de plantas isoladas para o cultivar IAC Airan.

Resultados de seletividade do herbicida em análise na cultura do milho foram também obtidos em trabalho realizado por Karam et al. (2009) demonstrando que o tembotrione, entre outros herbicidas, apresentou menor efeito tóxico nos híbridos BRS 130, DKB 393A, DOW 2 A252, P30F53 e SPEED.

Figura 2. Fitotoxicidade das doses 0 (D1), 50,4 (D2), 100,8 (D3) e 201,6 (D4) g i.a. ha ${ }^{-1}$ do herbicida tembotrione em três cultivares de milho, IAC 8390 (Figura A), IAC Airan (Figura B) e IAC 8333 (Figura C), avaliados aos 7, 14, 21 e 28 dias após sua aplicação em V3.

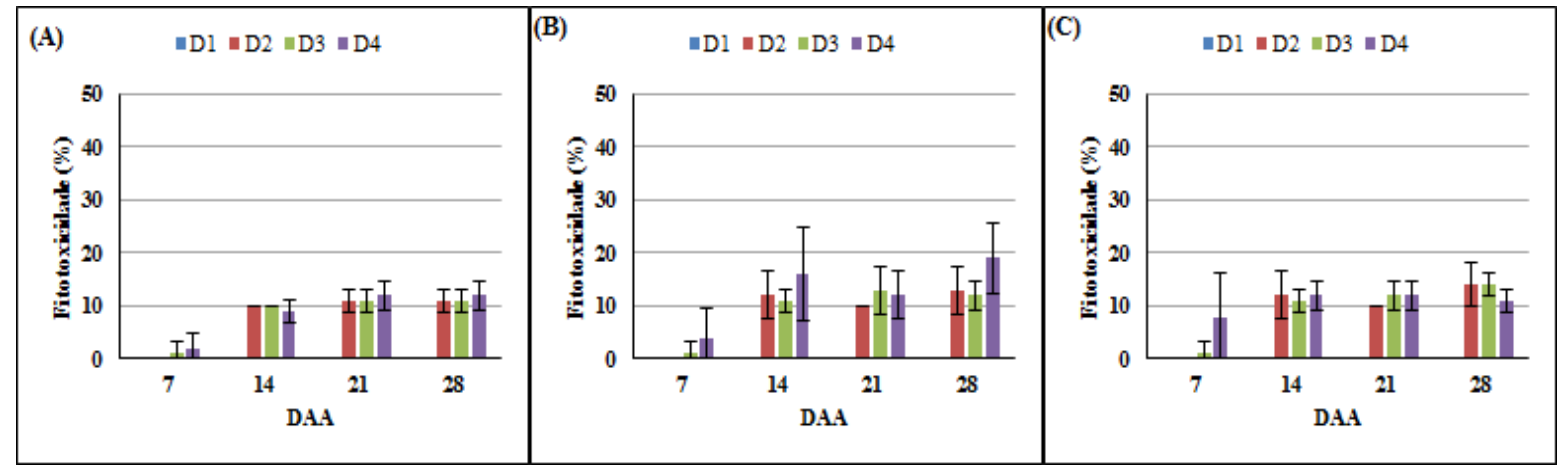

A aplicação do tembotrione no estádio V6 do milho evidenciou uma tendência de maior fitotoxidade, todavia, permaneceu no limite de $20 \%$ nos cultivares IAC 8390 e IAC 8333 . O cultivar IAC Airan, apresentou, na maior dose, nota de $32 \%$, aos 7 DAA, a qual foi reduzida no decorrer das avaliações. Em comparação ao primeiro período (V3), o cultivar IAC 8390 obteve em todas as doses, níveis de fitotoxidade mais baixos, entre 10\% e 14\%, aos 21 DDA (Figura 3).

Figura 3. Fitotoxicidade das doses 0 (D1), 50,4 (D2), 100,8 (D3) e 201,6 (D4) g i.a. ha ${ }^{-1}$ do herbicida tembotrione em três cultivares de milho, IAC 8390 (Figura A), IAC Airan (Figura B) e IAC 8333 (Figura C), avaliados aos 7, 14 e 21 dias após sua aplicação em V6.
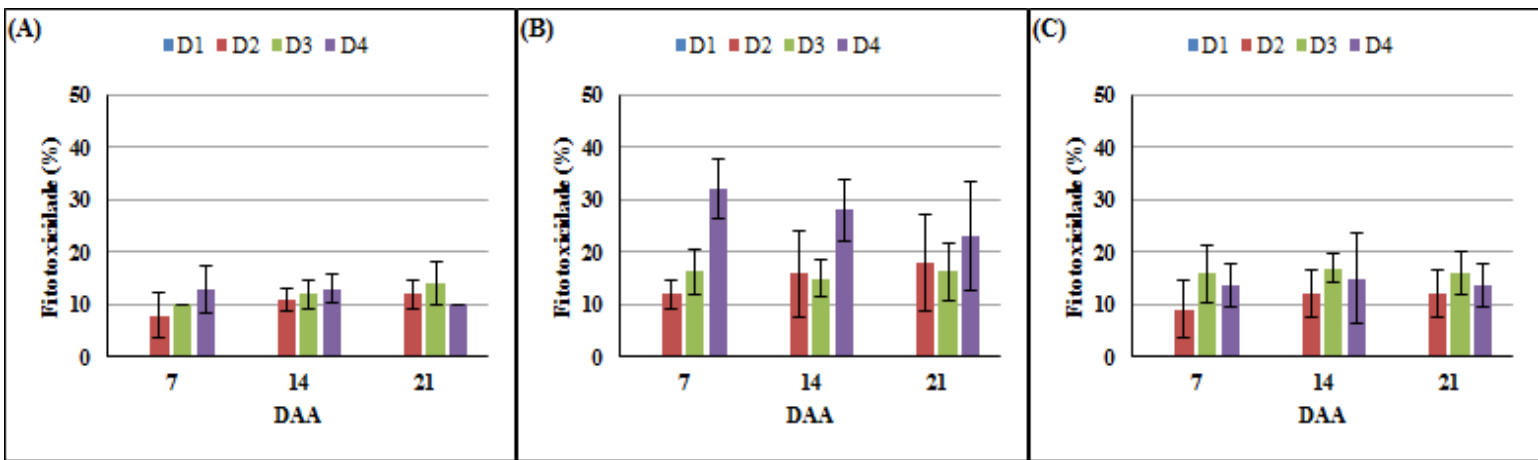
Embora tenham ocorrido sintomas característicos do herbicida nas plantas de milho, ocorreu rápida recuperação dos cultivares. Neste sentindo, esses sintomas não resultaram na redução da estatura das plantas, na altura de espigas, na massa de 100 grãos e finalmente na produtividade de grãos (Tabela 3). Assim, diferentemente do nicosulfuron, no qual a resposta dos cultivares à aplicação do herbicida é bastante variável (CAVALIERI et al., 2008), o tembotrione tem sido seletivo aos cultivares de milho (SPADER et al., 2008; KARAM et al., 2009;).

Comparando os valores relativos aos dois períodos de aplicação do herbicida (V3 e V6) para massa de 100 grãos e rendimento de espiga (Tabela 3 e 4), é possível perceber diferenças de pouco valor prático, levando a constatar que os cultivares avaliados não sofreram efeitos prejudiciais em relação à produtividade corroborando com os resultados de Karam et al. (2009).

Tabela 3. Altura da planta (ALTP), altura de inserção da espiga (ALTE), população de plantas (POP), produtividade de grãos (PRODG), massa de 100 grãos (M100) e peso do hectolitro (PH) em três cultivares de milho, duas épocas de aplicação e quatro doses do herbicida tembotrione.

\begin{tabular}{|c|c|c|c|c|c|c|}
\hline \multirow{2}{*}{ Tratamentos } & ALTP & ALTE & POP & $\mathbf{P H}$ & M100 & PRODG \\
\hline & \multicolumn{6}{|c|}{ 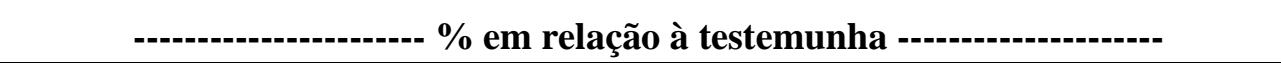 } \\
\hline \multicolumn{7}{|l|}{ Doses } \\
\hline 0,0 & $100,0 \mathrm{a}$ & $100,0 \mathrm{a}$ & $100,0 \mathrm{a}$ & $100,0 \mathrm{a}$ & $100,0 \mathrm{a}$ & $100,0 \mathrm{a}$ \\
\hline 50,4 & $101,1 \mathrm{a}$ & $104,8 \mathrm{a}$ & $98,5 \mathrm{a}$ & $100,1 \mathrm{a}$ & $100,5 \mathrm{a}$ & $100,2 \mathrm{a}$ \\
\hline 100,8 & $101,1 \mathrm{a}$ & $102,2 \mathrm{a}$ & $100,6 \mathrm{a}$ & $100,1 \mathrm{a}$ & $101,3 \mathrm{a}$ & $104,5 \mathrm{a}$ \\
\hline 201,6 & $101,9 \mathrm{a}$ & $99,6 \mathrm{a}$ & $103,1 \mathrm{a}$ & $100,0 \mathrm{a}$ & $99,8 \mathrm{a}$ & $105,6 \mathrm{a}$ \\
\hline \multicolumn{7}{|l|}{ Cultivares } \\
\hline IAC 8390 & $99,7 \mathrm{a}$ & $98,3 \mathrm{a}$ & $97,6 \mathrm{~b}$ & $100,4 \mathrm{a}$ & 100,6 a & $100,9 \mathrm{a}$ \\
\hline IAC Airan & $101,8 \mathrm{a}$ & $104,5 \mathrm{a}$ & $99,8 \mathrm{ab}$ & $99,6 \mathrm{a}$ & $100,1 \mathrm{a}$ & $102,8 \mathrm{a}$ \\
\hline IAC 8333 & $101,6 \mathrm{a}$ & $102,3 \mathrm{a}$ & $104,3 \mathrm{a}$ & $100,1 \mathrm{a}$ & $100,5 \mathrm{a}$ & $104,1 \mathrm{a}$ \\
\hline \multicolumn{7}{|l|}{ Estádio } \\
\hline V3 & $100,06 \mathrm{~b}$ & $101,97 \mathrm{a}$ & $101,96 \mathrm{a}$ & 99,98 a & $99,06 \mathrm{~b}$ & $101,8 \mathrm{a}$ \\
\hline V6 & $102,06 \mathrm{a}$ & $101,45 \mathrm{a}$ & $99,17 \mathrm{a}$ & $100,15 \mathrm{a}$ & $101,75 \mathrm{a}$ & $103,4 \mathrm{a}$ \\
\hline Média & 101,06 & 101,71 & 100,56 & 100,06 & 100,41 & 102,60 \\
\hline
\end{tabular}

Médias seguidas da mesma letra na coluna não diferem entre si pelo teste t(LSD) a 5\% de probabilidade.

Tabela 4. Rendimento de espiga em função das doses e da interação entre cultivares e épocas de aplicação do herbicida tembotrione.

\begin{tabular}{|c|c|c|c|}
\hline Época & IAC 8390 & IAC Airan & IAC 8333 \\
\hline V3 & 101,16 a $\mathrm{A}$ & 100,79 a $\mathrm{A}$ & 99,25 b B \\
\hline \multirow[t]{5}{*}{ V6 } & 100,77 a A & 100,06 a $\mathrm{A}$ & 100,53 a A \\
\hline & \multicolumn{3}{|c|}{ Doses } \\
\hline & 0 & $50,4 \quad 100,8$ & 201,6 \\
\hline & \multicolumn{3}{|c|}{------------- g i.a. ha ${ }^{-1}$} \\
\hline & $100 \mathrm{a}$ & $100,45 \mathrm{a} \quad 100,79 \mathrm{a}$ & $100,47 \mathrm{a}$ \\
\hline
\end{tabular}

Médias seguidas da mesma letra minúsculas na linha e maiúscula na coluna não diferem entre si pelo teste t (LSD) a $5 \%$ de probabilidade.

Dan et al. (2010) mostraram que a seletividade do tembotrione para a cultura do milheto é dependente da dose utilizada e do estágio fenológico da mesma no momento de aplicação. Neste mesmo 
estudo, dentro do intervalo de doses estudado, a maior dose $\left(252 \mathrm{~g}\right.$ i.a. ha $\left.^{-1}\right)$ afetou a produção de grãos em $39 \%$ e $25 \%$ e provocou redução da altura das plantas em aplicações realizadas com quatro e sete folhas expandidas respectivamente. Esses resultados reforçam que tolerância da cultura a um herbicida é dependente do cultivar, do estádio fenológico no momento da aplicação, da dose utilizada entre outros fatores, assim como verificado para tolerância da cultura do milho ao herbicida nicosulfuron por LópezOvejero et al. (2003) e Cavalieri et al. (2008). Em nosso trabalho as pequenas diferenças de fitotoxicidade entre os cultivares confirmam a dependência dos fatores como dose, estádio de desenvolvimento das plantas e do efeito varietal sobre os herbicidas a cultura. Todavia, também confirma os resultados de Spader et al. (2008), Karam et al. (2009) no qual o tembotrione tem-se mostrado altamente seletivo à cultura do milho. Por outro lado, neste trabalho em torno de $1 \%$ das plantas apresentaram sintomas severos dos herbicidas, o que vai ao encontro com os dados observados por Schuelter et al. (2018) no qual a aplicação desse herbicida em campos de linhagens e de populações segregantes, obtidas a partir de alguns cruzamentos com genótipos tolerantes, revelaram o aparecimento de sintomas de fitotoxicidade, indicando a existência de fatores genéticos que conferem sensibilidade ao nicosulfuron e tembotrione. Neste contexto, tanto os sintomas apresentados quanto o efeito sobre algumas variáveis das plantas, provavelmente, está relacionado ao fato dos cultivares utilizados possuirem maior variabilidade genética e maior desuniformidade entre as plantas.

\section{CONCLUSÃO}

Nas condições em que o trabalho foi realizado, conclui-se que o herbicida tembotrione apresentou baixa fitotoxicidade aos cultivares de milho IAC 8390, IAC Airan e IAC 8333, independentemente da dose ou época de aplicação em relação ao estádio de desenvolvimento da cultura (V3 ou V6), podendo o mesmo ser empregado no controle de plantas daninhas na cultura do milho quando se opta pelo uso desses cultivares.

\section{REFERÊNCIAS}

BLANCO, H. G.; ARAÚJO, J. B. M.; OLIVEIRA, D. A. Estudo sobre a competição de plantas daninhas na cultura do milho (Zea mays L.). IV - Determinação do período de competição. Arquivo Instituto Biológico, v. 43, n. 3/4, p. 105-14, 1976.

BUZATTI, W. J. S. Seletividade de híbridos de milho aos herbicidas. Informativo Fundação ABC, v. 2 n. 8, p. 8-10, 2000.

CAVALIERI, S. D.et al. Tolerância de híbridos de milho ao herbicida nicossulfuron. Planta Daninha, v. 26, n. 1, p. 203-214, 2008.

CIIAGRO - Centro Integrado de Informações Agrometeorológicas. Rede meteorológica automática. 2018. Disponível em: 〈http://www.ciiagro.org.br/ema/index.php?id=91>. Acesso em: 7 fev. 2019.

CRUZ, C. D.; PEREIRA FILHO, I. A.; QUEIROZ, L. R. Milho - cultivares para 2013/2014. Embrapa Milho e Sorgo. 2014. Disponível em: 〈http://www.cnpms.embrapa.br/erros/autoriza.html〉. Acesso em: 10 fev. 2019.

CONAB - Companhia Nacional De Abastecimento. Acompanhamento da Safra Brasileira de Grãos. 2018. Disponível em: < http://www.conab.gov.br>. Acesso em: 20 out. 2018. 
CONSTANTIN, J.; OLIVEIRA, R.S. Dessecação antecedendo a semeadura direta pode afetar a produtividade. Informações Agronômicas, n.109, p. 14-15, 2005.

DAN, H. A.et al. Seletividade do nicossulfuron e da mistura com atrazine na cultura do milho. Revista Agrarian, v. 3, n. 10, p. 243-252, 2010.

DAN, H. A.et al. Seletividade de herbicidas aplicados na pós-emergência da cultura do milheto (Pennisetum glaucum). Revista Brasileira de Milho e Sorgo, v. 8, n. 3, p. 297-306, 2009.

DAN, H. A.et al. Seletividade do herbicida tembotrione à cultura do milheto. Planta Daninha, v. 28, n. 4, p. 793-799, 2010.

DAN, H. A.et al. Controle de plantas daninhas na cultura do milho por meio de herbicidas aplicados em pré-emergência. Pesquisa Agropecuária Tropical, v. 40, n. 4, p. 388-393, 2010.

DAMIÃO FILHO, C. F.; MÔRO, F. V.; TAVEIRA, L. R. Respostas de híbridos de milho ao nicossulfuron, 1 - Aspectos biológicos e da produção. Planta Daninha, v. 14, n. 1, p. 3-13, 1996.

EMBRAPA- Empresa Brasileira de Pesquisa Agropecuária. Cultivo do Milho. 8 ed. Sete Lagoas: EMBRAPA, CNPMS, 2012. (Sistema de produção, 1). Disponível em: < http://sistemasdeprodução.cnptia.embrapa.br/FontesHTML/Milho/CultivodoMilho 8ed/economia.htm>. Acesso em: 23 out. 2018.

EMBRAPA - Empresa Brasileira de Pesquisa Agropecuária. Cultivo do Milho. 9 ed. Sete Lagoas: EMBRAPA, CNPMS, 2015. (Sistema de Produção, 1). Disponível em: < https://www.spo.cnptia.embrapa.br/conteudo?p_p_id=conteudoportlet_WAR_sistemasdeproducaolf6_1ga 1 ceportlet\&p_p_lifecycle $=0 \& p \_p \_s t a t e=$ normal $\& p \_p \_$mode $=v i e w \& p \_p \_c o l \_i d=$ column 1\&p_p_col_count=1\&p_r_p_-76293187_sistemaProducaoId=7905\&p_r_p_-996514994_topicoId=8662> Acesso em: 1 set. 2018.

FANCELLI, A. L.et al. Influência do uso de herbicidas no rendimento e nos componentes de produção de milho. In: CONGRESSO NACIONAL DE MILHO E SORGO, 22., Recife, 1998. Resumos [...]. Recife: IPA/ABMS/EMBRAPA, 1998.

FAO - Food as Agricultural Organization. FAOSTAT data base for agriculture. Disponível em: < http://faostat.fao.org/site/339/default.aspx >. Acesso em: 10 nov. 2018.

GUBBIGA, N. G.; WORSHAM, A. D.; COBLE, H. D. Effect of Nicosulfuron on johnsongrass (Sorghum halepense) control and corn (Zea mays) performance. Weed Technology, v. 9, n. 1, p. 3574-3581, 1995.

GROSSMANN, K.; EHRHARDT, T. On the mechanism of action and selectivity of the corn herbicide topramezone: a new inhibitor of 4-hydroxyphenylpyruvate dioxygenase. Pest Management Science, v. 63 , n. 5, p. 429-439.

KARAM, D.et al. Características do tembotrione na cultura do milho. Sete Lagoas - MG: Embrapa Milho e Sorgo, 2009. (Embrapa Milho e Sorgo. Circular Técnica, 129). Disponível em: < https://www.embrapa.br/busca-de-publicacoes/-/publicacao/658664/caracteristicas-do-herbicidatembotrione-na-cultura-do-milho>. Acesso em: 17 ago 2018.

KOZLOWSKI, L. A. Período crítico de interferência das plantas daninhas na cultura do milho baseado na fenologia da cultura. Planta Daninha, v. 20, n. 3, p. 365-372, 2002.

LÓPEZ OVEJERO, R. F.et al. Seletividade de herbicidas para a cultura de milho (Zea mays) aplicados em diferentes estádios fenológicos da cultura. Planta Daninha, v. 21, n. 3, p. 413-419, 2003.

MCMULLAN, P. M.; BLACKSHAW, R. E. Postmergence green foxtail (Setaria viridis) control in corn (Zea mays) in western Canada. Weed Technol., v. 9, n. 1, p. 37-43, 1995. 
MORTON, C. A.; HARVEY, R. G. Sweet corn (Zea mays) hybrid tolerance to nicosulfuron. Weed Technology, v. 6, n. 1, p. 91-96, 1992.

NICOLAI, M. Desempenho da cultura de milho (Zea mays $L$.) submetida a aplicação de herbicidas pós-emergentes, em diferentes situações de manejo. 2004. 42f. Dissertação (Mestrado em Fitotecnia) Universidade de São Paulo, Piracicaba - SP. 2004.

OLIVEIRA, M. F. Comportamento dos herbicidas no ambiente. In: OLIVEIRA JUNIOR, R.S.; CONSTANTIN, J. Plantas daninhas e seu manejo. Guaiba: Agropecuaria, 2001. p. 315-355.

OLIVEIRA, R. S.; CONSTANTIN, J. Plantas daninhas e seu manejo. Guaíba: Agropecuária, 2001, 362 p.

SCHUELTER, A. R.et al. Tolerância genética de linhagens de milho aos herbicidas tembotrione e nicosulfuron. Revista Brasileira de Milho e Sorgo, v. 17, n. 2, p. 317-327, 2018.

SPADER, V.et al.Seletividade de herbicidas pós emergentes em híbridos de milho. In: CONGRESSO BRASILEIRO DA CIÊNCIA DAS PLANTAS DANINHAS, 26.; CONGRESO DE LA ASOCIACION LATINOAMERICANA DE MALEZAS, 18., 2008, Ouro Preto. Anais[...] Sete Lagoas: SBCPD: Embrapa Milho e Sorgo, 2008.

SPADER, V.; VIDAL, R. A. Seletividade e dose de injúria econômica de nicossulfuron aplicado em diferentes estádios de desenvolvimento da cultura do milho. Ciência Rural, v. 31, n. 6, p. 929-934, 2001.

VELINI, E. D.et al.Avaliações dos efeitos do herbicida clomazone, aplicado em pós emergência inicial, sobre o crescimento e produtividade de soqueira de canade-açúcar (Saccaharum officinarum) cv. SP 711406. Revista Stab, v. 10, n. 4, p. 13-16, 1992.

VIDAL, R. A. Herbicidas: mecanismos de ação e resistência de plantas. Porto Alegre: R. A. Vidal, 1997. $165 \mathrm{p}$.

WILLIAMS, M.M.; PATAKY, J.K. Genetic basis of sensitivity in sweet corn to tembotrione. Weed Science, v. 56, p. 364-370, 2008. 